\title{
GLOBAL TRANSPORTATION OF FOODSTUFFS
}

\begin{abstract}
Maritime transport belongs to the modes of transportation which ensures intercontinental transport of passengers and cargo between the continents. Not only it is very effictive, but it also enables to carry a huge volume of cargo. The transportation of temperature controlled cargo started in the 19th century with the transportation of meat. Until then, transportations of goods under the influence of the temperature were realised only between regions. It is necessary to care about proper handling, cooling, packaging and the compatibility during the transportation of temperature-controlled cargo.
\end{abstract}

Keywords: Perishable cargo, foodstuffs, cargo packing.

\section{Introduction}

Temperature controlled cargo is the cargo that must be transported at a specific temperature to avoid any damage. Globally, fruit and vegetables are the most dominant types of cargo transported in containers with controlled temperature. Other commodities such as meat, fish and seafood, dairy products, flowers and medicines are transported too [1]

The most important factors for the carriage of the cargo under controlled temperature are:

- regulation of temperature,

- air conditioning,

- humidity,

- proper packaging [2].

\section{Temperature controlled cargo}

Temperature controlled cargo can be divided into these categories:

- pharmaceutical products,

- live animals,

- chemical products,

- flowers and plants,

- foodstuffs:

fresh food (e.g. fruit, vegetables),

- chilled food (e.g. meat, butter, cheese),

- frozen food (e.g. frozen meat, ice cream) [2].

This article focuses mainly on the last mentioned group of temperature controlled cargo - foodstuffs. Currently, food is transported mainly for long distances. This transportation is cheap, but also very slow. Therefore, only the transportation of foodstuffs with a long shelf life is realised. The proper handling of goods and right storage is necessary for prevention of cargo damage. It is also important to reduce the time for loading and unloading processes for minimising the delays. This is especially important in the case of handling the refrigerated and frozen foods that perish very quickly. For this reason all the necessary transport documents must be prepared to avoid delays.

Some cargo such as meat must be stored either refrigerated between 0 and $-2{ }^{\circ} \mathrm{C}$ or frozen at $-18^{\circ} \mathrm{C}$ or lower. Other cargo such as fresh fruit must be stored at temperatures from $-3{ }^{\circ} \mathrm{C}$ to $+16^{\circ} \mathrm{C}$ to ensure the goods will arrive in the best condition [3].

\section{Perishable food}

The constant checking of the temperature in the containers and in the holds of the vehicle during the transportation of food is crucial. There are two main factors that influence the durability of the shipment: temperature and relative humidity. For example, vegetable with forced air exchange can lose a certain percentage of water because of the decrease of relative humidity, and it will reflect on a weight. The loss is negligible only in the case of the low-cost products transportation, but during the transportation the products such as coffee, cocoa beans, etc., it is necessary to set the ventilation so as the relative humidity is at the required level.

\footnotetext{
* Peter Piala, Andrea Galierikova, Andrej David

Department of Water Transport, Faculty of Operation and Economics of Transport and Communications, University of Zilina, Slovakia E-mail: peter.piala@fpedas.uniza.sk
} 


\subsection{Cargo refrigerating during the transport}

Perishable cargo must be cooled to the specific temperature before the loading due to avoiding damage of cargo as a result of too long refrigeration of the cargo space. The bananas and citrus fruits which do not perish quickly may be cooled in the cargo space.

Figure 1 presents a model situation - citrus fruit in carton boxes placed on pallets. This fruit was transported to a warehouse with temperature $23-25{ }^{\circ} \mathrm{C}$. The required temperature of fruit is 4 to $-5^{\circ} \mathrm{C}$. The temperature of air in the warehouse was stabilised after 48 hours, but the temperature of the fruit surface stabilised after 127 hours. The temperature of the fruit depends on the location of carton boxes on the pallet [4].

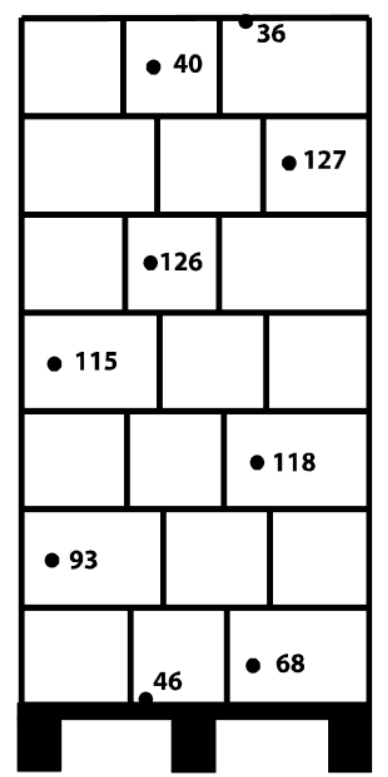

Fig. 1 The time in hours required for the cooling of the individual layers of citrus fruit packed in cartons and placed on pallets. Source: [4]

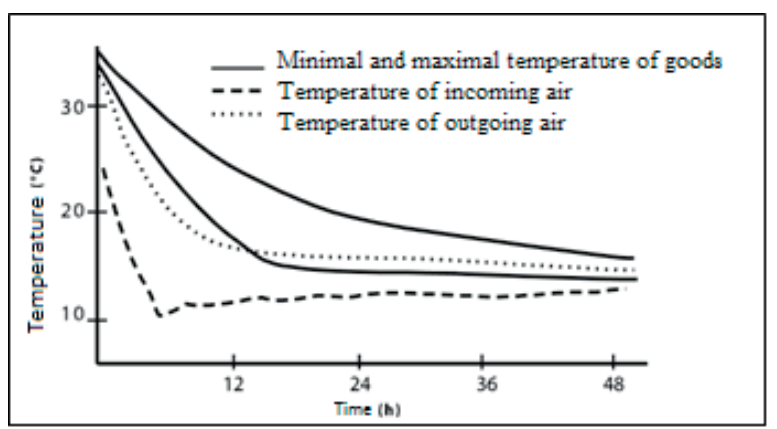

Fig. 2 Cooling bananas

Source: [4]
The cooling device can refrigerate the bananas during the transportation to the required temperature $\left(13\right.$ to $\left.14{ }^{\circ} \mathrm{C}\right)$ very quickly [4]. Figure 2 presents the cooling process of bananas.

\section{Fresh fruit and vegetables stored on pallets (cartons on pallets)}

The air always flows by the path of the least resistance. During the loading cargo into the container, there must be gaps or "chimneys" for ensuring better air circulation throughout the cargo. The air that does not pass through cargo cannot adequately remove the heat produced in the respiratory processes.

If the cargo does not cover the whole T-floor, some type of filling material must be used. This material must be placed on the places where is stored no cargo. The correct placing of goods ensures air flow in the space and makes air circulating throughout the cargo to ensure proper air flow. The cargo should always be placed a few millimetres from the wall of the container to ensure the lateral air flow [5 - 7]. Figure 3 shows the deployment of cargo and airflow between the cargo in the container.

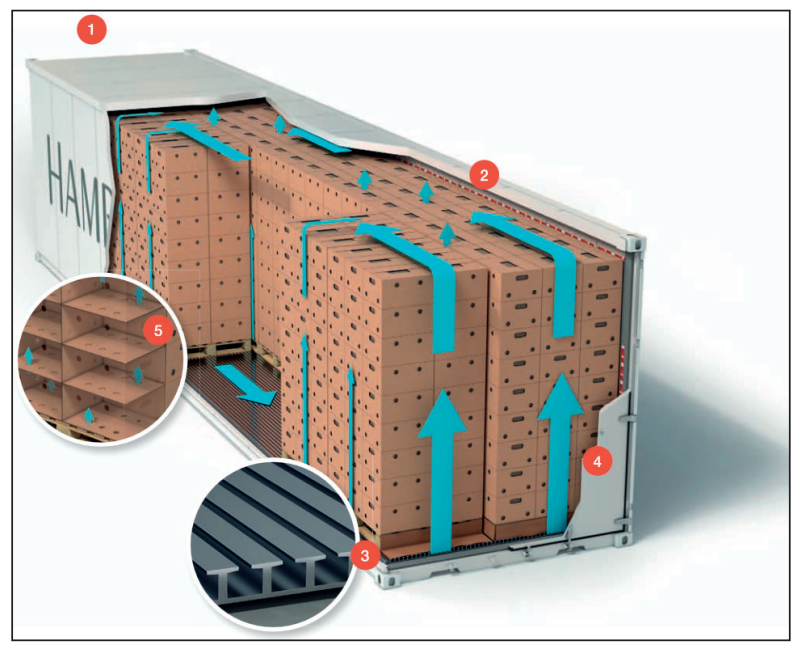

Fig. 3 The deployment of cargo in the container Source: [5]

Figure description:

1. Cooling unit.

2. The maximal height - the height cannot exceed red line that presents the maximal allowed height of the cargo. This line provides adequate space for air circulation over the stored [cargo].

3. T-floor - the most common form of the floor is known as the T-floor (T-shaped cross section, which forms the floor).

4. Doors

5. Airflow - arrows show the flow of air inside the reefer containers. 


\subsection{Cargo packing}

Packaging is an important step for sustaining the quality of the foodstuffs. Important packaging factors are:

- ventilation,

- protection agents (from contamination, abuse and dehydration)

- strength,

- insulation,

- marking [5 and 8].

Packaging facilitates the handling and distribution. Labels on packages can be a powerful marketing tool (design, colour, etc.). There are two types of packages:

1. Inner packaging - direct contact with the product.

2. The outer packaging - normally contains a number of inner packaging.

Requirements for internal packaging of refrigerated and frozen products are different from fruit and vegetables. The most important characteristics of packaging materials used for refrigerated or frozen products are:

- water vapour permeability,

- gas permeability,

- physical properties.

Figure 4 presents airflow between cartoons on the pallet.

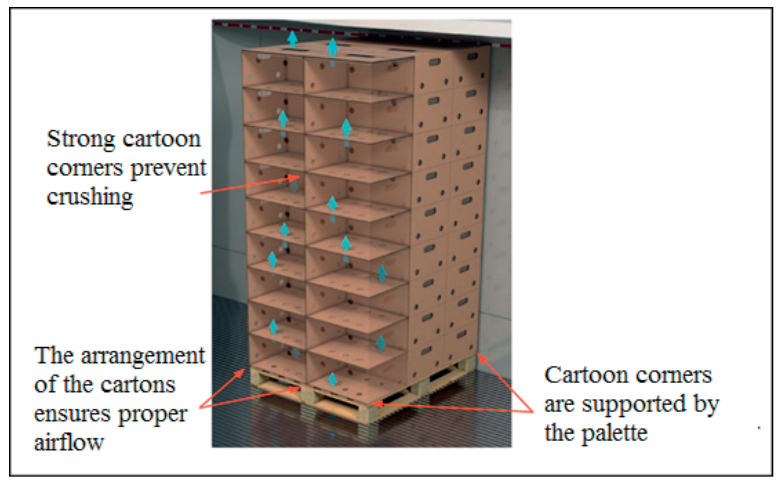

Fig. 4 Airflow between cargos on the pallet Source: [5]
Packaging must withstand:

- rough handling,

- compression of the accumulated weight of stacked packages,

- shocks and vibrations during the transportation,

- high humidity during cooling, transportation and storage.

Cartons for fresh fruit and vegetables require airflow by the gaps at the top and bottom of the boxes. The properties such as: quantity, location, size and shape of the air gaps depend on the product. The wax-impregnated cardboard or other materials that do not lose power in a high humidity environment should be used. The strength of the carton is in its corners. Stacking boxes directly to each other, it is recommended and ensures minimising of crushing cartons [5 and 9].

\section{Recommended transport conditions and the approximate shelf life of refrigerated cargo}

The following Table 1 shows the recommended settings (temperature, ventilation and dehumidification) and approximate shelf life for products transported and stored in standard freezer containers [2 and 10].

\section{Foodstuffs compatibility}

Table 2 shows food that can be or cannot be transported together in one and the same container or stored in the same room. For example, unripe bananas or potatoes cannot be transported or stored with another food. Conversely, asparagus can be transported or stored together with apples, apricots and kiwi [2 and 10].

\section{Conclusion}

In the paper we have focused on temperature-controlled cargo and its division into the categories. There is need to

Recommended settings [2]

Table 1

\begin{tabular}{|c|c|c|c|c|c|}
\hline Cargo & Temperature $\left({ }^{\circ} \mathrm{C}\right)$ & Ventilation $\mathrm{m} 3 / \mathrm{h}$ & Relative humidity (\%) & $\begin{array}{c}\text { Dehuminication } \\
\text { On/OFF }\end{array}$ & $\begin{array}{c}\text { Approximate shelf life } \\
\text { after harvest }\end{array}$ \\
\hline Apples & -1 to +4 & $10-60$ & $90-95$ & $\mathrm{OFF}$ & 1 to 7 months \\
\hline Avocado & +4 to +13 & $30-60$ & $85-95$ & $\mathrm{OFF}$ & 2 to 3 weeks \\
\hline Bananas & +13 to 14.4 & $25-60$ & $90-95$ & OFF & 18 to 22 days \\
\hline Blueberries & -1 to 0 & $0-10$ & $90-95$ & $\mathrm{OFF}$ & 10 to 14 days \\
\hline Carrot & 0 to +2 & $10-20$ & $90-98$ & OFF & 1 to 9 months \\
\hline
\end{tabular}




\begin{tabular}{|c|c|c|c|c|c|c|c|c|c|}
\hline & $\frac{\frac{0}{2}}{\frac{2}{2}}$ & 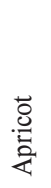 & 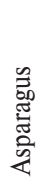 & 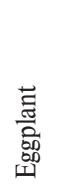 & 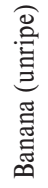 & $\underset{\varpi}{\varpi ్ ల ~}$ & 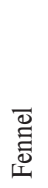 & 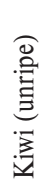 & 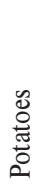 \\
\hline \multicolumn{10}{|l|}{ Apples } \\
\hline \multicolumn{10}{|l|}{ Apricot } \\
\hline \multicolumn{10}{|l|}{ Asparagus } \\
\hline \multicolumn{10}{|l|}{ Eggplant } \\
\hline \multicolumn{10}{|l|}{ Banana(unripe) } \\
\hline \multicolumn{10}{|l|}{ Bean } \\
\hline \multicolumn{10}{|l|}{ Fennel } \\
\hline \multicolumn{10}{|l|}{ Kiwi (unripe) } \\
\hline Potatoes & & & & & & & & & \\
\hline
\end{tabular}

follow the rules to avoid the damage of temperature-controlled cargo during the transport and handling operations. The proper cooling, packaging and compatibility of each type of cargo were mentioned in the paper. Ignoring the rules can cause the cargo damage and thus lead to large financial losses. We have also focused on foodstuffs compatibility that defines which types of cargo can be transported together, or not. This compatibility is influenced by chemical attributes of transported cargo.

\section{References}

[1] Review of Maritime Transport 2015. online: http://unctad.org/en/PublicationsLibrary/rmt2015_en.pdf, 09 November 2016.

[2] SIR-C. online: www.sir-c.se/getfile.ashx?cid=257832\&cc=3\&refid=2, 06 November 2016

[3] Refrigerated and insulated containers - Transport Information Service. Online: http://www.tis-gdv.de/tis_e/containe/arten/ kuehlcon/kuehlcon.htm. 01 November 2016.

[4] ZAJAC, P., CAPLA, J., GOLIAN, J., BELEJ, L.: Hygiene Distribution and Sale of Food (in Slovak), Slovak University of Agriculture, 2013, ISBN 978-80-552-0970-8.

[5] Reefer guide, online: http://www.hamburg-sued.com/group/media/sharedmedia/dokumente/brochures/Reefer_guide.pdf, 20 November 2016.

[6] ZALEZAK, M.: Technology in Ports and Transshipment Areas, 8 - Container Terminals, EDIS : University of Zilina, 2001, ISBN 80-7100-867-2.

[7] RODRIGUE, J.-P., COMTOIS, C., SLACK, B.: The Geography of Transport Systems, $3^{\text {rd }}$ ed., 2013, 411 p., ISBN 978-0-41582253-4.

[8] SUlGAN, M., SOSEDOVA, J.: Procurement of Materials and Components for Manufacturing Activity, Communications Scientific Letters of the University of Zilina, vol. 16, No. 2, 2014, 58-62, ISSN 1335-4205.

[9] STOPFORD, M.: Maritime Economics, Routledge : Oxon 2009, 816 p., ISBN 978-0-415-27558-3.

[10] PIALA, P., DAVID, A.: Transport of Tropical Fruits to Central Europe, Our Sea, vol. 63, No. 2, 2016, 62-65, ISSN 04696255. 